\title{
Applying Configurational Theory to Build a Typology of Ethnocentric Consumers
}

\author{
Sven Feurer, Institute of Information Systems and Marketing (IISM) \\ University/Institution: Karlsruhe Institute of Technology (KIT) \\ Karlsruhe, Germany, sven.feurer@gmx.de
}

Elisa Baumbach, Department of Marketing, University/Institution: University of Mannheim Mannheim, Germany, baumbach@bwl.uni-mannheim.de

Arch G. Woodside, Department of Marketing, University/Institution: Wallace E. Carroll School of Management, Boston College, Town/City: Chestnut Hill, MA, USA, arch.woodside @bc.edu

Corresponding author: Sven Feurer

Corresponding Author's Email: sven.feurer@gmx.de

Sven Feurer Elisa Baumbach Arch G. Woodside (2016),"Applying configurational theory to build a typology of ethnocentric consumers", International Marketing Review, Vol. 33 Iss 3 pp. 351 - 375. Permanent link to this document: http://dx.doi.org/10.1108/IMR-03-2014-0075 


\begin{abstract}
Purpose: "Scientists' tools are not neutral” (Gigerenzer 1991, p. 264): This paper demonstrates that the choice of methodology shapes the way we think about and craft theory in international marketing research.
\end{abstract}

Design/methodology/approach: The authors use fuzzy-set qualitative comparative analysis (fsQCA) of panel data from 3,859 consumers to disclose distinct sets of antecedents that are sufficient for explaining three types of consumer ethnocentrism (CET). The authors then contrast the results with those from multiple regression analysis.

Findings: The authors highlight the value of fsQCA in identifying combinations of antecedents that are sufficient for explaining the respective types of CET.

Research limitations/implications: The authors call for a paradigm shift from symmetrical to asymmetrical thinking in data analysis and crafting theory.

Practical implications: The findings help global business strategists in their market entry decisions and in their targeting and segmentation efforts.

Originality/value: The results expand our understanding of CET and challenge conventional net-effects thinking about its antecedents.

Keywords: algorithm; analysis; Boolean; consumer; equifinality; ethnocentrism 


\section{Applying Configurational Theory to Build a Typology of Ethnocentric Consumers}

The aim of this study is to demonstrate the validity of an algorithm perspective for deepening understanding of beliefs held by individuals high in CET. CET is a trait-like individual property that relates to the appropriateness of buying foreign-made or imported products (Shimp and Sharma, 1987). Specifically, the study here reports an exemplary exposition on configurations of antecedent conditions associating with high CET cases (i.e., individuals). This research illustrates how fsQCA-a method of configural analysis that grounds on an asymmetrical way of thinking about relationships among antecedent conditions-allows for a nuanced understanding of one of the fundamental constructs of international business research and its antecedents (cf. Birkinshaw et al., 2011). This illustration is done using panel data from 1994-1996. The intent is not to report on the current impact of CET but to show how three unique segments of consumers who are high in ethnocentrism occur.

The principles of property space analysis (Lazarsfeld, 1937) and equifinality (von Bertalanffy, 1968) are central tenets of configural theory — a given end state can be reached by many potential means. Property space analysis aids theory construction and testing via a descriptive role of building types from the "compounds of attributes" of concepts. Each unique combination of the attributes of the included concepts provides a separate compound concept including spaces indicating the presence of one attribute coupled with the absence of a second attribute. "Conventional usage arrays the component attributes in rows and columns to construct an associated property space. Every cell in that space captures a possible grouping of the attributes of the concepts being organized" (Elman, 2005, p. 296). The theory and findings in the study in this article support the conjecture following from property space analysis that three unique types of individuals high in CET (according to what they advocate) are identifiable. 
The principle of equifinality is the proposal that several (or at least a few) means or complex configurations of antecedent conditions lead to the same outcome. The study here proposes and finds that a few (rather than one) complex antecedent conditions (i.e., algorithms) associate with each of three unique types of individuals high in CET.

FsQCA (Ragin, 2009) is a relatively new methodological approach that, to date, appears rarely in top-tier journals that relate to international marketing (see Pajunen, 2008 for a notable exception). Carrying out fsQCA is particularly worthwhile given the inconsistent empirical findings for several antecedents of CET (see Shankarmahesh, 2006 for an integrative review), some of which may be attributable to the methodological artifacts of multiple regression analysis (MRA). Indeed, the results from this study challenge conventional wisdom about antecedents of CET.

"Scientists' tools are not neutral" (Gigerenzer, 1991, p. 264), meaning that research methods and instruments shape the way we think about, craft, and test theory. International business researchers, too, are not beyond allowing their tools influence their theories. Once scientific tools become accepted by the research community, their underlying paradigms often go unquestioned. Consider extant research on antecedents of CET that typically relies on quantitative methods, including correlation analysis (e.g., De Ruyter et al., 1998; Javalgi et al., 2005; Shimp et al., 1995;), MRA (e.g., Josiassen et al., 2011), and structural equation modeling (e.g., Cleveland et al., 2009; Jiménez and San Martín, 2010; Suh and Kwon, 2001; Vida et al., 2008). By using these tools, scholars wittingly or unwittingly adopt a symmetrical way of thinking about relationships between antecedents and outcomes (Author 3, 2013). More specifically, researchers expect high levels of the antecedent variables (either as a direct or interaction expression) to correspond to high levels of CET and vice versa. However, in real life, 
relationships are seldom symmetrical, that is, causes leading to the presence of CET may be different from those leading to the absence of CET (cf. Fiss, 2011). Rather, the presence of a specific combination of antecedents may result in sufficiency, but not necessity, of CET (cf. Author 3, 2010). Consequently, Author 3 (2013) calls for a paradigm shift from symmetrical to asymmetrical thinking in data analysis and crafting theory.

The remainder of this article is organized as follows. Section 2 introduces a typology of distinct types of CET that draws on the proposed two-dimensional conceptualization of CET. The following section describes the research methodology. Here, the authors introduce fsQCA and discusses potential advantages of this methodology over MRA in investigating antecedents of CET. The subsequent sections provide the empirical results using fsQCA and, additionally, using MRA. The authors close by discussing and contrasting the results and by providing implications for researchers and practitioners.

\section{A Configural View on Consumer Ethnocentrism and Its Antecedents}

CET is one of the most heavily researched consumer characteristics in international business research in recent years (e.g., Alden et al., 2013; Cleveland et al., 2009; Javalgi et al., 2005; Jiménez and San Martín, 2010; Moon and Jain, 2002; Josiassen et al., 2011; Oberecker and Diamantopoulos, 2011). Prior research conceptualizes CET as a form of protectionism at a consumer level (Verlegh, 2007). Individuals showing CET argue that the choice for a foreignmade product may harm the domestic economy or may be simply unpatriotic (Shimp and Sharma, 1987). Several studies confirm a direct or indirect relationship between CET and negative attitudes towards buying foreign products or brands (e.g., Alden et al., 2013; De Ruyter et al., 1998; Evanschitzky et al., 2008; Javalgi et al., 2005; Josiassen et al., 2011). 
Shimp and Sharma's (1987) one-dimensional conceptualization of CET does not account for consumers' beliefs with regard to whether the consumers themselves or the government should put forms of protectionism into practice. However, a 2010 USA Today/Gallup poll shows that the American public divides fiercely over the role of the government in general: more than 80 percent of Republican voters say that the government is trying to do too much that should be left to individuals, while almost two-out-of-three Democrat voters say that the government should do more to solve the country's problems (Newport and Mendes, 2010). Based on this notion, the present study puts forward a typology that allocates ethnocentric consumers along two dimensions of CET: (1) the extent to which consumers support consumer-controlled protectionism, and (2) the extent to which consumers support government-controlled protectionism. The proposed typology contains three distinct types of CET. First, ethnocentric consumers who support consumer-controlled protectionism but not government-controlled protectionism (CCPs) believe that the consumers themselves should be exclusively in charge of putting forms of protectionism into practice (e.g., by deliberately buying domestic products). Second, ethnocentric consumers who support government-controlled protectionism but not consumer-controlled protectionism (GCPs) believe that the government should be exclusively in charge of putting forms of protectionism into practice (e.g., by introducing quotas or tariffs). Third, consumers may be highly supportive of both consumer-controlled and governmentcontrolled protectionism (CCP•GCPs; the mid-level dot "•" indicates the logical "and" combination). As Fiss (2011) emphasizes, such a typology is highly beneficial for organizing complex cause-effect relationships. 


\section{Research Method}

Dataset, Sample Composition, and Property Space Analysis

The present study uses secondary data from the DDB Needham Life Style Survey. The data contain $300+$ items of which we select 8 that relate to antecedents of CET. Six items are socio-demographic variables (i.e., age, education, gender, income, race, size of city of residence) and two are socio-psychological variables (i.e., openness to other cultures, conservatism). We analyze a subset of 3,859 respondents of the years 1994-1996. To control for the potential influence of the political environment on the subjects' opinions (e.g., Rosenblatt, 1964), the subsample comprises 50 percent of respondents residing in states that traditionally vote Democratic ("blue states"; e.g., New York) and 50 percent of respondents residing in states that traditionally vote Republican ("red states", e.g., Texas). Table 1 depicts the sample composition.

Table 1 here.

A property space analysis (Lazarsfeld, 1937) discloses the proportion of individuals that we label CCPs, GCPs, and CCP•GCPs. The dataset includes two six-point Likert-type items (anchored 1 = definitely disagree, $6=$ definitely agree) that capture the support of consumercontrolled protectionism ("Americans should always try to buy American products") and the support of government-controlled protectionism ("The government should restrict imported products") of CET. Table 2 depicts the property space. While the extremes with regard to CCPs and GCPs are few (1.9\% and .3\%, respectively), a focus on these individuals is beneficial to control for noise in the data. A large proportion of respondents $(31.7 \%)$ do fall within the upper- 
right quadrant indicating that they are rather CCPs than $\mathrm{CCP} \bullet \mathrm{GCPs}$, and 4.2 percent fall within the lower-left quadrant indicating that they are rather GCPs than CCP•GCPs.

Table 2 here.

\section{Measurement}

The six socio-demographic variables are measured on dichotomous nominal scales or ordinal scales (i.e., age, city size, education, gender, and income). Openness to other cultures is assessed on a six-point Likert scale (anchored $1=$ fully disagree, $6=$ fully agree) by a singleitem ("I am interested in the culture of other countries"). As a proxy for conservatism, we include political affiliation since it is a relevant indicator for different opinions on the role of the government (Newport and Mendes, 2010). Respondents'support of government-controlled protectionism and respondents' support of consumer-controlled protectionism is measured by six-point Likert scales as indicated previously. Table 3 summarizes all measurements.

Table 3 here.

\section{Fuzzy-set Qualitative Comparative Analysis}

The analysis applies fsQCA using fs/QCA 2.0 (Ragin et al., 2006). FsQCA (Ragin, 2009) is a technique that bridges quantitative, variable-oriented research methods, and qualitative, caseoriented research methods (Author 3, 2010; Pajunen, 2008). Variable-oriented methods (e.g., MRA) and case-oriented methods (e.g., fsQCA) follow different epistemological principles (Vis, 2012). MRA follows an "effects-of-causes" approach that seeks to estimates net effects of 
independent variables, but fsQCA follows a "causes-of-effects" that seeks to explain individual cases (cf. Mahoney and Goertz, 2006, p. 229). To accomplish these diverging goals, MRA disaggregates cases (i.e., ethnocentric consumers) into independent, analytically separate aspects whereas fsQCA compares cases as configurations of qualitative attributes (cf. Pajunen, 2008; Vis, 2012). In other words, fsQCA considers cases as meaningful yet complex configurations of events and structures (Ragin, 1997). Following an asymmetric way of thinking about relationships between variables, fsQCA yields different combinatory statements of antecedents that relate to high outcome values (Author 3, 2013; Ragin, 2009).

FsQCA offers potential advantages over MRA when investigating antecedents of CET. First, fsQCA is able to disclose complex sets of interactions in a comprehensible way. In fact, some of the inconsistencies in empirical findings with regard to CET and its antecedents (see Shankarmahesh, 2006) may be attributable to practical problems with MRA that relate to examining high-level interactions. To illustrate this issue, we adapt an example provided by Ragin (2004). A typical finding of an fsQCA on antecedents of CET may be the following: "When conditions A, B, and C are present, X causes CET, however, if any one of these conditions ( $\mathrm{A}, \mathrm{B}$, or $\mathrm{C})$ is absent, and $\mathrm{X}$ is also absent, then $\mathrm{Z}$ causes CET." This statement is multiple and conjunctive in nature and reflects the notional asymmetry of relationships under investigation. Arriving at the same statement with MRA involves a four-way interaction that is almost impossible to plot graphically. Furthermore, MRA would require a very large sample size and would potentially cause problems due to multi-collinearity (Ragin 1997). In fact, multicollinearity is inevitable for high numbers of variables in a regression model (Author 3, 2013). Given the large number of socio-psychological, economic, political, and demographic 
antecedents of CET that prior literature discusses (Shankarmahesh, 2006), fsQCA is adequate for overcoming potential problems that relate to multi-collinearity (Author 3, 2013; Vis, 2012). Analysis Plan

FsQCA allows us to address the varying degree to which cases belong to a given set (Pajunen 2008). To specify the degree of membership for each case, we generate a fuzzy-set score based on Boolean set theory and fuzzy-sets (Zadeh, 1965) with scores between 0 (full nonmembership) and 1 (full membership). A membership score of .50 marks the ambiguous score between non-membership and membership (Ragin, 2009). For all six-point Likert-type scales, we calibrate the original values of 1 to correspond with full non-membership (.01), and 6 to correspond with full membership (.99). The values 2 and 3 were calibrated with strong nonmembership (.20) and weak non-membership (.40); the values 4 and 5 were calibrated with weak membership (.60) and strong membership (.80), respectively. Variables measured at the ordinal level are calibrated similarly, depending on the number of categories. All dichotomous variables are calibrated to correspond with either full non-membership (.01) or full membership (.99). Table 4 shows the calibration of the variables into fuzzy-set scores.

Table 4 here.

Due to the conjunctive nature of the proposed types of CET, we use cross-tables to assign membership scores for CCPs, GCPs, and CCP•GCPs. Respondents showing strong support for both consumer-controlled protectionism and government-controlled protectionism receive high fuzzy-set scores for the $\mathrm{CCP} \cdot \mathrm{GCP}$ outcome (indicating strong or full membership). Respondents who strongly support government-controlled protectionism but not consumer-controlled 
protectionism receive high fuzzy-set scores for the GCP outcome, and respondents showing strong support for consumer-controlled protectionism but not for government-controlled protectionism receive high fuzzy-set scores for the CCP outcome. The fuzzy-set coding schemes for the respective outcomes appear in Table 5.

Table 5 here.

To analyze the results of our multiple fuzzy-set assessments, the raw data matrix is transformed into truth tables. We follow Ragin (2009) in constructing the truth tables. Starting from a multidimensional vector space with $2^{\mathrm{k}}$ corners (where $k$ represents the number of antecedent conditions), our initial truth tables consist of $2^{8}$ rows representing all possible combinations of antecedent conditions. Next, we identify the empirically relevant combinations of antecedents by specifying a frequency threshold based on the number of cases with greater than .50 memberships in each combination (Ragin, 2009). From the remaining combinations of antecedents, we select those showing high consistency, meaning that the combinations are subsets of high scores in the outcome. Ragin (2009) proposes that values smaller than .75 indicate substantial inconsistency and thus he recommends a consistency threshold of .85 or higher.

\section{Results}

\section{Combinations of Antecedents of $C C P \cdot G C P s$}

Figure 1 illustrates that, given the sample size, our data encompasses a large number of cases of CCP•GCPs. Hence, the study applies Ragin's (2009) recommendation to select a relatively high frequency threshold. We set the frequency threshold to 6, meaning that only 
combinations that are displayed by more than five cases are classified as empirically relevant (covering $89 \%$ of all cases). Subsequently, we choose a consistency threshold of .90, hereby selecting those combinations for which the degree of empirical evidence is highly consistent with the set theoretic relation in question (Ragin, 2009).

Table 6 presents the resulting truth table which contains the eight antecedents that are under investigation (columns) and, in this case, 16 combinations of antecedents (rows) or paths, each of which sufficiently explain the presence of CCP•GCP. As Ragin (2009) recommends, we report the intermediate solution. Note that black circles (“•”) indicate the presence of antecedent, white circles (“O”) indicate the negation of antecedents, and blank cells represent ambiguous ones or "don't care" conditions. For example, path no. 1 reveals that "whites with low education, low income, from rural areas who are non-republican affiliated" is a sufficient combination of antecedents of $\mathrm{CCP} \cdot \mathrm{GCPs}$.

Furthermore, Table 6 includes indices of consistency and coverage. Consistency is akin to significance in statistical hypothesis testing (Author 3 and Author, 2012) with values ranging from 0 to 1 . High consistency indicates that the specific combination of antecedents ("consistency") or the solution as a whole ("solution consistency") is sufficient for explaining $\mathrm{CCP} \cdot \mathrm{GCPs}$ (Ragin, 2009). Coverage indices also range from 0 to 1 and are akin to effect size in statistical hypothesis testing (Author 3 and Author, 2012). Coverage indices measure the proportion of CCP•GCPs that is explained by the complete solution ("solution coverage"), by each term of the solution ("raw coverage"), or by each individual solution term ("unique coverage"). All consistency indices exceed .80 , indicating that all combinations of antecedents and the solution as a whole are sufficient for explaining CCP•GCPs (Ragin, 2009). Raw coverage indices for the 16 combinations of antecedents range from .09 to .26 . 
Table 6 here.

Several findings are worth discussing in considering the alternative equifinal solutions in Table 6. First, the absence of cultural openness can be found in 12 out of 16 combinations while being ambiguous for the remaining four conditions. Second, 13 out of 16 combinations include whites and no combination includes non-whites. Third, several conditions sufficient for explaining $\mathrm{CCP} \cdot \mathrm{GCPs}$ exist for females and for males, for old and young, for high and low education, and for republicans and democrats. Low income prevails in most combinations; however, one combination encompasses white females with high incomes. Last, several combinations exist for both rural and its negation (i.e., urban).

\section{Combinations of Antecedents of CCPs}

Due to a small number of cases showing $\mathrm{CCP}$ and the phenomenon being unfamiliar to researchers, the authors set the frequency threshold to three (covering 97\% of all cases). As before, the consistency threshold is set to .90 . The resulting truth table (Table 7) encompasses seven combinations that are sufficient for explaining CCPs. All consistency indices are larger than .80 . However, the coverage indices are relatively low for the overall solution (.12) and for the combinations of antecedents (.04-.06). Hence, the proportion of CCPs that is explained by the solution and by the specific combinations of antecedents is relatively small. This result suggests that the CCPs can only to a small extent be explained by the antecedents included.

Turning to the specific combinations of antecedents, several findings are to be noted. Six out of seven combinations pertain to non-white females, and five out of seven combinations pertain to non-white females who have Democrat as political affiliation. Furthermore, a mixed 
picture occurs for all other variables, including cultural openness. Two combinations exist for CCPs in which individuals are in fact open for other cultures. More combinations include high income and high education than their negation.

Table 7 here.

\section{Combinations of Antecedents of GCPs}

As done for CCPs, the study includes constructing a truth table for GCPs by setting the frequency threshold to three (covering 95\% of all cases). The consistency threshold is set to .80 because the consistency scores are generally lower for GCPs then for CCPs and CCP•GCPs. The truth table (Table 8) encompasses two combinations of antecedents of which both pertain to young non-whites with high income and high education who are not open to other cultures. However, both combinations have low raw coverage indices (.07 and .08). Although their consistency indices are high (.84 and .81$)$, the solution consistency is .76 and thus slightly below the .80 criterion. Thus, the antecedents included in the present study only modestly explain GCPs.

Table 8 here.

\section{Additional Multiple Regression Analyses}

We now focus our interest on net effects of antecedent variables or their interactions on the respective dependent variables while partialling out the effects of other antecedent variables. For the analyses with MRA, no changes are made with regard to the sample or the selection of 
antecedent variables. $\mathrm{CCP} \cdot \mathrm{GCP}$ is operationalized by a summary index of the responses to the items "Americans should always try to buy American products" and "The government should restrict imported products". For CCP, the item that measures the support of governmentcontrolled protectionism is reversed before summing up the values of the items. Similarly, for GCP, the item that measures the support of consumer-controlled protectionism is reversed before summing up the values of the items.

To simplify the analysis and interpretation, all antecedent variables are dummy-coded (after median-splitting the continuous variables) as follows: race (white $=1$, non-white $=0$ ), gender $($ male $=1$, female $=0)$, age $($ old $=1$, young $=0)$, education $($ high education $=1$, low education $=0$ ), income (high income $=1$, low income $=0$ ), city size (rural $=1$, urban $=0$ ), political affiliation (republican $=1$, non-republican), and cultural openness (openness to cultures $=1$, no openness to cultures $=0$ ).

Regressing a given dependent variable on eight antecedent variables causes potential problems with regard to interactions and multi-collinearity. For the analysis here, it is virtually impossible to account for all possible interactions. Even limiting the analysis to two-way interactions would require 28 interaction terms and would inevitably cause problems that associate with multi-collinearity. These problems should be evident even assuming that researchers always base the inclusion of interactions on theoretical reasoning. As a consequence, this analysis dispenses from an inclusion of interaction terms and examines the direct effects only. Without the interaction terms, the resulting maximum variance inflation factor (VIF) is low (1.120), indicating that multi-collinearity is not an issue.

Table 9 depicts the MRA results with $\mathrm{CCP} \cdot \mathrm{GCP}$ as dependent variable $(\mathrm{F}(8,3820)=$ $42.685 ; p<.001)$. With the exception of political affiliation, all effects are significant (all 
$p<.05)$. White, old, and rural relates positively to $\mathrm{CCP} \cdot \mathrm{GCP}$, and male, high education, high income and openness to cultures relates negatively to $\mathrm{CCP} \bullet \mathrm{GCP}$.

Table 9 here.

A subsequent analysis included CCP as the dependent variable (Table 10). However, the global F-test yields an $\mathrm{F}$ value that is not significant $(\mathrm{F}(8,3820)=1.687, p>.05)$. Of all antecedent variables, only old (versus young) relates positively to CCP. Last, we perform an analysis with GCP as the dependent variable. Note that the scale of GCP equals the reverse of the CCP scale. Hence, due to the aforementioned symmetry of the approach, MRA yields the identical coefficients except for reversed algebraic signs.

Table 10 here.

\section{Discussion}

\section{Comparison of Findings}

A comparison of the findings for $\mathrm{CCP} \cdot \mathrm{GCP}$ reveals that fsQCA (Table 6) provides a different picture compared to MRA (Table 9). The MRA presents net effects of the antecedents on $\mathrm{CCP} \cdot \mathrm{GCP}$ and suggests that white, old, and rural are the antecedents that relate positively to $\mathrm{CCP} \cdot \mathrm{GCP}$, whereas male, high education, high income and openness to cultures are the antecedents that relate negatively to $\mathrm{CCP} \cdot \mathrm{GCP}$. In general, these findings are in line with the current state of research (Shankarmahesh, 2006). In contrast, the fsQCA draws a much more heterogeneous picture of CCP•GCPs. In fact, some manifestations of antecedents appear in 
combinations with other antecedents one would not expect to sufficiently explain $\mathrm{CCP} \cdot \mathrm{GCPs}$ based on the current state of research. For example, prior research suggests that $\mathrm{CCP} \bullet \mathrm{GCPs}$ relates to a low openness to other cultures. Indeed, the absence of cultural openness appears in 12 out of 16 combinations. However, in four combinations of antecedents, openness to other cultures is ambiguous and, hence, irrelevant. As for race, where empirical evidence from prior research is mixed (Shankarmahesh 2006), the fsQCA results generally support research that finds minorities to be more favorable to foreign-made products than the majority. The great majority of 13 out of 16 combinations include whites and no combination includes non-whites. However, the fsQCA also reveals three combinations of antecedents for which belongingness to the respective racial groups is irrelevant.

Regarding the level of education, intriguingly, three combinations of antecedents include highly-educated consumers, and education status is irrelevant for describing CCP•GCPs in four combinations, indicating that education may have a more complex impact on CET than thought previously. Concerning age, in accordance with the majority of prior research, 8 combinations of antecedents that explain $\mathrm{CCP} \cdot \mathrm{GCPs}$ include male respondents, but 6 combinations of antecedents include female respondents. Furthermore, the fsQCA reveals that CCP•GCPs in some cases are young, live in urban areas, and are of high-income.

As for the CCPs, the results of the MRA and the fsQCA again differ noticeable. Ignoring the low global F value, MRA solely shows that CCPs are rather females than males (Table 10). The fsQCA yields more insights (Table 7). Six out of seven combinations of antecedents of CCPs pertain to non-white females, and five out of seven pertain to non-white females who are non-republican. Moreover, the majority of combinations include high-education and high- 
income individuals. Notably, some CCPs are in fact open for other cultures. The proportions of young vs. old individuals and consumers living in rural vs. urban areas are rather balanced.

The analysis of CGPs with MRA results merely in a reversion of the algebraic signs of the coefficients compared to the analysis of CCPs (Table 8). Hence, the MRA solely suggests that CGPs are rather males than females. In contrast, the results from the fsQCA tell a somewhat different story. Although Table 8 depicts two combinations of antecedents of which both pertain to young non-whites with high income and high education who are not open to other cultures, the results needs to be seen in the light of the low solution consistency value and therefore need to be treated with caution.

Contributions, Limitations, and Future Research

This empirical study contributes to the literature on CET by putting forward a new typology of ethnocentric consumers that encompasses CCPs, GCPs, and CCP•GCPs. This typology is a step forward in organizing the complex cause-effect relationships between CET and its antecedents. The results show that these types of CET relate to distinct sets of antecedents and partly challenge conventional wisdom with regard to the antecedents of CET that Shankarmahesh (2006) discusses.

As a consequence, Shimp and Sharma's (1987) conceptualization of CET may need broadening to encompass the two dimensions of consumer-controlled protectionism and government-controlled protectionism. This broadening implies that the existing operationalization of CET (i.e., the CETSCALE) needs further development. Otherwise, a consumer who scores high on only one dimension may not be recognized as showing high CET. An improved measurement for CET would also be beneficial on the managerial front. Here, the current practice may lead managers to misestimate the market potential in the target segments. 
As prior literature (e.g., Oberecker and Diamantopoulos, 2011; Shankarmahesh, 2006;

Shimp and Sharma, 1987) discusses, managers may use the insights from this research to inform their targeting and segmentation efforts more effective in terms of entry strategy and marketing communication programs. In this respect, CCPs may need more careful attention than GCPs because CCPs show stronger adverse reactions to foreign-made products. However, an active management of GCPs' attitudes may be worthwhile to reduce the pressure on policymakers to protect the domestic economy.

The present study has several limitations that provide avenues for further research. First, the dataset contains panel data and thus fails to provide an a priori theoretical rationale for the proposed two-dimensionality. Hence, we call for further research to test the propositions made in this article based on theory and with primary data. Second, the dataset contains data from 19941996 and thus the findings may not be representative of attitudes held currently. Third, the study is limited by the items available in the DDB Needham Life Style Survey. Future research needs to test the proposed conceptual framework with newer data, in different contexts, using the established CETSCALE (Shimp and Sharma, 1987), and in terms of predictive validity (i.e. using holdout samples to test the accuracy of alternative models).

\section{Conclusion}

As "scientists' tools are not neutral" (Gigerenzer 1991, p. 264), the mere selection of alternative innovative methodologies can contribute to and challenge knowledge in different streams of literature. The present study illustrates that a paradigm shift from symmetrical to asymmetrical thinking in data analysis and crafting theory yields valuable new insights for the field of international business research in general and for research on CET in particular. Specifically, this study investigates antecedents of distinct types of CET based on a typology that 
differentiates ethnocentric consumers by the extent to which they support government action or consumer action to protect the domestic economy. The authors employ fsQCA to identify combinations of antecedents that are sufficient for explaining the respective types of CET and contrast the results with those derived by a standard MRA approach. The findings highlight the great potential that asymmetrical, case-oriented methodologies like fsQCA offer for advancing the international business research agenda. Researchers should not avoid standard quantitative approaches but complement them with these alternative methodologies to identify complex configurations of antecedents (e.g., Author 3, 2013). Valuable new insights and advances in theory are the likely outcomes. 


\section{References}

Alden, D.L., Kelley, J.B., Riefler, P., Lee, J.A. and Soutar, G.N. (2013), “The Effect of Global Company Animosity on Global Brand Attitudes in Emerging and Developed Markets: Does Perceived Value Matter?”, Journal of International Marketing, Vol. 21 No. 2, pp. 17-38. Author 3 (2010).

Author 3 (2012).

Author 3 and Author (2013).

Birkinshaw, J., Brannen, M.Y. and Tung, R.L. (2011), "From a distance and generalizable to up close and grounded: Reclaiming a place for qualitative methods in international business research", Journal of International Business Studies, Vol. 42 No. 5, pp. 573-581.

Cleveland, M., Laroche, M. and Papadopoulos, N. (2009), “Cosmopolitanism, consumer ethnocentrism, and materialism: An eight-country study of antecedents and outcomes", Journal of International Marketing, Vol. 17 No. 1, pp. 116-146.

De Ruyter, K., van Birgelen, M. and Wetzels, M. (1998), “Consumer ethnocentrism in international services marketing”, International Business Review, Vol. 7 No. 2, pp. 185-202.

Elman, C. (2005), “Explanatory Typologies in Qualitative Studies of International Politics”, International Organization, Vol. 59 No. 2, pp. 293-326.

Evanschitzky, H., von Wangenheim, F., Woisetschläger, D., Blut, M. (2008), “Consumer ethnocentrism in the German market“, International Marketing Review, Vol. 25 No. 1, pp. $7-32$.

Fiss, P.C. (2011), "Building better causal theories: A fuzzy set approach to typologies in organization research", Academy of Management Journal, Vol. 54 No. 2, 393-420 
Gigerenzer, G. (1991), "From tools to theories: A heuristic of discovery in cognitive psychology", Psychological Review, Vol. 98 No. 2, pp. 254-267.

Javelin, R.G., Khare, V.P., Gross, A.C., and Scherer, R.F. (2005), “An application of the consumer ethnocentrism model to French consumers", International Business Review, Vol. 14 No. 3, pp. 325-344.

Jiménez, N.H. and San Martín, S. (2010), “The role of country-of-origin, ethnocentrism and animosity in promoting consumer trust. The moderating role of familiarity", International Business Review, Vol. 19 No. 1, pp. 34-45.

Josiassen, A., Assaf A.G. and Karpen, I.O. (2011), "Consumer ethnocentrism and willingness to buy”, International Marketing Review, Vol. 28 No. 6, pp. 627-646.

Lazarsfeld, P.F. (1937), "Some remarks on the typological procedures in social research", Zeitschrift für Sozialforschung, Vol. 6 No. 1, pp. 119-139.

Mahoney, J. and Goertz, G. (2006), “A tale of two cultures: Contrasting quantitative and qualitative research", Political Analysis, Vol. 14 No. 3, pp. 227-249.

Moon, B.J, and S.C Jain (2002), "Consumer processing of foreign advertisements: roles of country-of-origin perceptions, consumer ethnocentrism, and country attitude", International Business Review, Vol. 11 No. 2, pp. 117-138.

Newport, F. and Mendes, E. (2010), "Republicans, democrats still fiercely divided on role of gov't", Gallup Politics, available at: http://www.gallup.com/poll/141056/RepublicansDemocrats-Fiercely-Divided-Role-Gov.aspx (accessed 20 September, 2013).

Oberecker, E.M. and Diamantopoulos, A. (2011), “Consumers' Emotional Bonds with Foreign Countries: Does Consumer Affinity Affect Behavioral Intentions?” Journal of International Marketing, Vol. 19 No. 2, pp. 45-72. 
Pajunen, K. (2008), “Institutions and Inflows of Foreign Direct Investment: A Fuzzy-Set Analysis”, Journal of International Business Studies, Vol. 39 No. 4, pp. 652-669.

Ragin, C.C. (2004), “Turning the Tables: How Case-Oriented Research Challenges VariableOriented Research”, in Brady, H.E. and Collier, D. (Eds.), Rethinking Social Inquiry: Diverse Tools, Shared Standards, Rowan \& Littlefield, Lanham, MD, pp. 123-138.

Ragin, C.C. (2009), "Qualitative comparative analysis using fuzzy sets (fsQCA)”, in Rihoux, B. and Ragin, C.C. (Eds.), Configurational Comparative Methods: Qualitative Comparative Analysis (QCA) and Related Techniques, Sage Publications, Thousand Oaks, CA, pp. 87121.

Ragin, C.C., Drass, K.A. and Davey, S. (2006), Fuzzy-set/qualitative comparative analysis 2.0, Tucson, Arizona: Department of Sociology, University of Arizona.

Rosenblatt, P.C. (1964), “Origins and effects of group ethnocentrism and nationalism”, Journal of Conflict Resolution, Vol. 8 No. 2, pp. 131-146.

Shankarmahesh, M.N. (2006), “Consumer ethnocentrism: An integrative review of its antecedents and consequences", International Marketing Review, Vol. 23 No. 2, pp. 146172.

Shimp, T.A. and Sharma, S. (1987), “Consumer ethnocentrism: Construction and validation of the CETSCALE”, Journal of Marketing Research, Vol. 24 No. 3, pp. 280-289.

Suh, T. and Kwon, I.-W.G. (2002), “Globalization and reluctant buyers”, International Marketing Review, Vol. 19 No. 6, pp. 663-680.

Verlegh, P.W.J. (2007), "Home country bias in product evaluation: The complementary roles of economic and socio-psychological motives”, Journal of International Business Studies, Vol. 38 No. 3, pp. 361-373. 
von Bertalanffy, L. (1968). General systems theory, Braziller, New York.

Vis, B. (2012), "The comparative advantages of fsQCA and regression analysis for moderately large-N analyses”, Sociological Methods \& Research, Vol. 41 No. 1, pp. 168-198.

Zadeh, L.A. (1965), "Fuzzy sets”, Information and Control, Vol. 8 No. 3, pp. 338-353. 


\section{Table 1}

Sample composition (subsample of the DDB Needham Life Style Survey 1994-1996)

\begin{tabular}{|c|c|c|c|c|c|c|c|c|c|}
\hline \multirow{2}{*}{$\begin{array}{l}\text { State of } \\
\text { Residence }\end{array}$} & \multirow[t]{2}{*}{ Overall } & \multicolumn{2}{|c|}{ Gender } & \multicolumn{2}{|c|}{ Age } & \multicolumn{2}{|c|}{ Income } & \multicolumn{2}{|c|}{ Education } \\
\hline & & male & female & $\begin{array}{l}\leq 30 \\
\text { years }\end{array}$ & $\begin{array}{c}>30 \\
\text { years }\end{array}$ & $\begin{array}{c}<\mathrm{US} \$ \\
50,000\end{array}$ & $\begin{array}{l}\geq \mathrm{US} \$ \\
50,000\end{array}$ & $\begin{array}{l}\leq \text { high } \\
\text { school }\end{array}$ & $\begin{array}{l}>\text { high } \\
\text { school }\end{array}$ \\
\hline $\mathrm{red}^{\mathrm{a}}$ & $\begin{array}{r}1,931 \\
(50 \%)\end{array}$ & $\begin{array}{r}895 \\
(46 \%)\end{array}$ & $\begin{array}{r}1,036 \\
(54 \%)\end{array}$ & $\begin{array}{r}347 \\
(18 \%)\end{array}$ & $\begin{array}{r}1,584 \\
(82 \%)\end{array}$ & $\begin{array}{r}1,273 \\
(66 \%)\end{array}$ & $\begin{array}{r}658 \\
(34 \%)\end{array}$ & $\begin{array}{r}744 \\
(39 \%)\end{array}$ & $\begin{array}{r}1,187 \\
(61 \%)\end{array}$ \\
\hline blue $^{b}$ & $\begin{array}{r}1,928 \\
(50 \%)\end{array}$ & $\begin{array}{r}888 \\
(46 \%)\end{array}$ & $\begin{array}{r}1,040 \\
(54 \%)\end{array}$ & $\begin{array}{r}271 \\
(14 \%)\end{array}$ & $\begin{array}{r}1,657 \\
(86 \%)\end{array}$ & $\begin{array}{r}1,025 \\
(53 \%)\end{array}$ & $\begin{array}{r}903 \\
(47 \%)\end{array}$ & $\begin{array}{r}661 \\
(34 \%)\end{array}$ & $\begin{array}{r}1,267 \\
(66 \%)\end{array}$ \\
\hline totals & $\begin{array}{r}3,859 \\
(100 \%)\end{array}$ & $\begin{array}{r}1,783 \\
(46 \%)\end{array}$ & $\begin{array}{r}2,076 \\
(54 \%)\end{array}$ & $\begin{array}{r}618 \\
(16 \%)\end{array}$ & $\begin{array}{r}3,241 \\
(84 \%)\end{array}$ & $\begin{array}{c}2,298 \\
(60 \%)\end{array}$ & $\begin{array}{l}1,561 \\
(40 \%)\end{array}$ & $\begin{array}{r}1,405 \\
(36 \%)\end{array}$ & $\begin{array}{r}2,454 \\
(64 \%)\end{array}$ \\
\hline
\end{tabular}

a Arizona, Arkansas, Kansas, Kentucky, Mississippi, Montana, Utah, South Carolina, Tennessee, Texas; ${ }^{\mathrm{b}}$ California, New York 


\section{Table 2}

Property space configuration of CCP•GCPs, CCP• GCPs, and GCP•CCPs:

Share of Americans in DDB Needham Life Style Survey (1994-1996; n = 3,859)

\begin{tabular}{|c|c|c|c|c|c|c|c|}
\hline \multirow{8}{*}{ 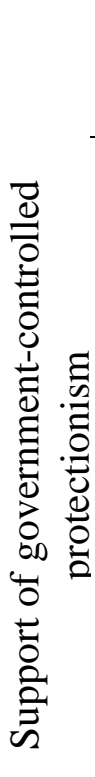 } & & \multicolumn{6}{|c|}{ Support of consumer-controlled protectionism } \\
\hline & & 1 & 2 & 3 & 4 & 5 & 6 \\
\hline & 1 & $\begin{array}{c}\text { non- } \\
\text { ethnocentrists } \\
2.3 \%\end{array}$ & $1.7 \%$ & $1.8 \%$ & $2.2 \%$ & $1.3 \%$ & $\begin{array}{c}\mathrm{CCP} \cdot \mathrm{GCP} \\
1.9 \%\end{array}$ \\
\hline & 2 & $.5 \%$ & $1.8 \%$ & $2.5 \%$ & $4.0 \%$ & $3.2 \%$ & $1.8 \%$ \\
\hline & & $.6 \%$ & $.9 \%$ & $3.7 \%$ & $7.7 \%$ & $5.8 \%$ & $3.8 \%$ \\
\hline & & $.4 \%$ & $.7 \%$ & $1.8 \%$ & $7.5 \%$ & $9.1 \%$ & $6.9 \%$ \\
\hline & 5 & $.2 \%$ & $.1 \%$ & $.3 \%$ & $2.3 \%$ & $5.4 \%$ & $6.3 \%$ \\
\hline & 6 & $\begin{array}{c}\mathrm{GCP} \bullet \mathrm{CCP} \\
.3 \%\end{array}$ & $.1 \%$ & $.3 \%$ & $.6 \%$ & $1.2 \%$ & $\begin{array}{c}\mathrm{CCP} \cdot \mathrm{GCP} \\
9.1 \%\end{array}$ \\
\hline
\end{tabular}

Note: Originally measured by 6-point Likert scales, anchored 1 (strongly disagree) and 6 (strongly agree). Support of consumer-controlled protectionism: "Americans should always try to buy American products." Support of government-controlled protectionism: "The government should restrict imported products." 


\section{Table 3}

\section{Items and Measurement}

\section{Condition \\ Types of CET}

support of consumer- conspro controlled protectionism

support of governmentcontrolled protectionism

govpro

$\mathrm{CCP}$

ethnocentric consumers who support consumercontrolled protectionism but not governmentcontrolled protectionism

ethnocentric consumers who support government-controlled protectionism but not consumer-controlled protectionism

Symbol Item

"Americans should always try to buy American products"

(Likert scale: $1=$ fully disagree, 6 = fully agree)

"The government should restrict imported products"

(Likert scale: $1=$ fully disagree, $6=$ fully agree)

conjunction of conspro (high) and govpro (high)

conjunction of conspro (high) and govpro (low)

conjunction of conspro (low) and govpro (high)

Antecedents

\begin{tabular}{|c|c|c|}
\hline gender & male & respondent's gender \\
\hline race & white & respondent's race \\
\hline income & highinc & respondent's annual household income \\
\hline city size & rural & size of city of respondent's residence \\
\hline olitical affiliation & repub & respondent's political affiliation \\
\hline education & highedu & respondent's level of education completed \\
\hline & old & respondent's age \\
\hline ltural openness & openculture & $\begin{array}{l}\text { "I am interested in the culture of other } \\
\text { countries" }\end{array}$ \\
\hline & & (Likert scale: $1=$ fully disagree, $6=$ fully agree) \\
\hline
\end{tabular}


Table 4

\section{Fuzzy-set coding schemes}

\begin{tabular}{|c|c|c|c|}
\hline Symbol & Original score & Fuzzy-set score & Variable label for fuzzy-set score \\
\hline conspro, & 1 & .01 & full non-membership \\
\hline govpro, & 2 & .20 & strong non-membership \\
\hline \multirow[t]{4}{*}{ openculture } & 3 & .40 & weak non-membership \\
\hline & 4 & .60 & weak membership \\
\hline & 5 & .80 & strong membership \\
\hline & 6 & .99 & full membership \\
\hline \multirow[t]{2}{*}{ male } & male & .99 & full membership \\
\hline & female & .01 & full non-membership \\
\hline \multirow[t]{2}{*}{ white } & white & .99 & full membership \\
\hline & non-white & .01 & full non-membership \\
\hline \multirow[t]{6}{*}{ highinc } & under $\$ 10,000$ & .01 & full non-membership \\
\hline & $\$ 10,000-\$ 19,999$ & .20 & strong non-membership \\
\hline & $\$ 20,000-\$ 34,999$ & .40 & weak non-membership \\
\hline & $\$ 35,000-\$ 49,999$ & .60 & weak membership \\
\hline & $\$ 50,000-\$ 79,999$ & .80 & strong membership \\
\hline & $\$ 80,000$ or more & .99 & full membership \\
\hline \multirow[t]{4}{*}{ rural } & Rural and towns $<50 \mathrm{k}$ & .99 & full membership \\
\hline & $50 \mathrm{k}-500 \mathrm{k}$ & .70 & strong membership \\
\hline & $500 \mathrm{k}-2 \mathrm{M}$ & .30 & strong non-membership \\
\hline & $>2 \mathrm{M}$ & .01 & full non-membership \\
\hline \multirow[t]{2}{*}{ repub } & republican & .99 & full membership \\
\hline & non-republican & .01 & full non-membership \\
\hline \multirow[t]{6}{*}{ highedu } & elementary school & .01 & full non-membership \\
\hline & attended high school & .20 & strong non-membership \\
\hline & graduated from high school & .40 & weak non-membership \\
\hline & attended college & .60 & weak membership \\
\hline & graduated from college & .80 & strong membership \\
\hline & post-graduate education & .99 & full membership \\
\hline \multirow[t]{6}{*}{ old } & 65 and older & .99 & full membership \\
\hline & $55-64$ & .80 & strong membership \\
\hline & $45-54$ & .60 & weak membership \\
\hline & $35-44$ & .40 & weak non-membership \\
\hline & $25-34$ & .20 & strong non-membership \\
\hline & $19-24$ & .01 & full non-membership \\
\hline
\end{tabular}


Table 5

\section{Fuzzy-set coding schemes of CCP•GCPs, CCPs, and CGPs}

\section{$\mathrm{CCP} \cdot \mathrm{GCPs}$}

Support of consumer-controlled protectionism

\begin{tabular}{|c|c|c|c|c|c|c|}
\hline \multirow{7}{*}{ 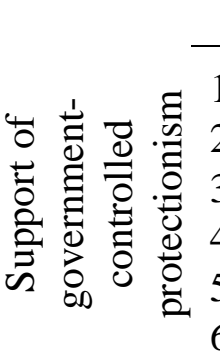 } & 1 & 2 & 3 & 4 & 5 & 6 \\
\hline & .01 & .01 & .01 & .01 & .01 & .01 \\
\hline & .01 & .20 & .20 & .20 & .20 & .20 \\
\hline & .01 & .20 & .40 & .40 & .40 & .40 \\
\hline & .01 & .20 & .40 & .60 & .60 & .60 \\
\hline & .01 & .20 & .40 & .60 & .80 & .80 \\
\hline & .01 & .20 & .40 & .60 & .80 & .99 \\
\hline
\end{tabular}

CCPs

Support of consumer-controlled protectionism

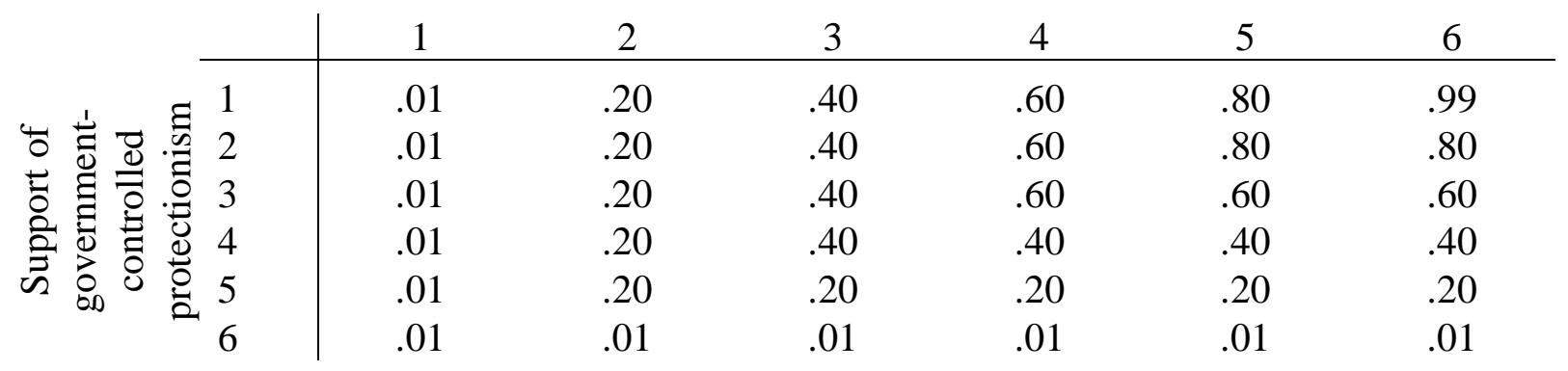

CGPs

Support of consumer-controlled protectionism

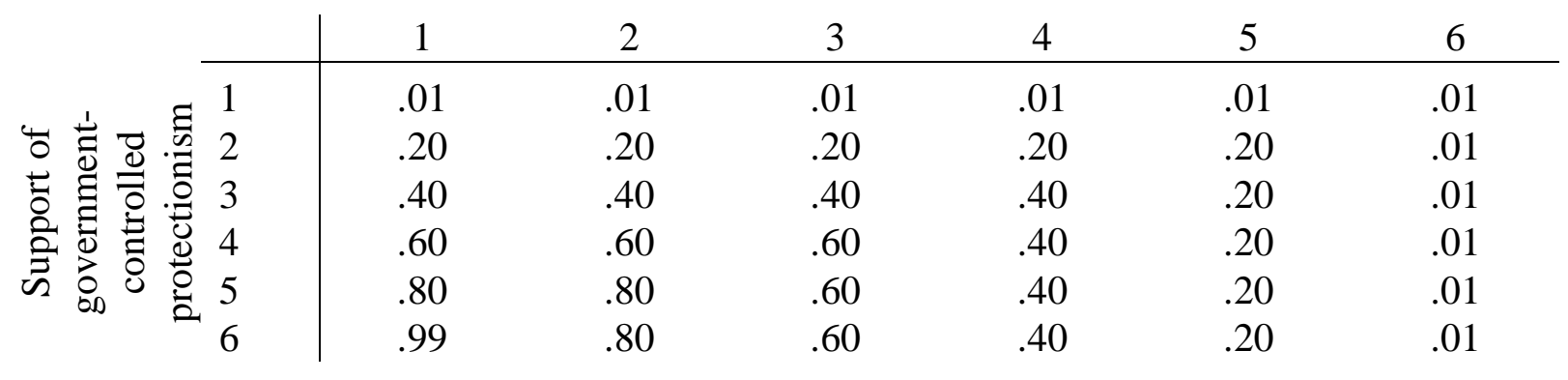

Note: Originally measured by 6-point Likert scales, anchored 1 (strongly disagree) and 6 (strongly agree). Support of consumer-controlled protectionism: "Americans should always try to buy American products". Support of government-controlled protectionism: "The government should restrict imported products" 
Table 6

Truth table for CCP•GCPs - intermediate solution

\begin{tabular}{|c|c|c|c|c|c|c|c|c|c|c|c|c|c|}
\hline \multirow[t]{2}{*}{ Path no. } & \multicolumn{8}{|c|}{ Antecedent (symbol) } & \multicolumn{2}{|c|}{ Coverage } & \multirow[t]{2}{*}{ Consistency } & \multicolumn{2}{|c|}{ Solution } \\
\hline & $\frac{\mathscr{A}}{\frac{3}{3}}$ & $\frac{\mathscr{U}}{\tilde{\Xi}}$ & $\frac{0}{0}$ & $\begin{array}{l}\vec{z} \\
\stackrel{D}{0} \\
\stackrel{000}{\Xi}\end{array}$ & $\begin{array}{l}\mathscr{\Xi} \\
. \Xi \\
. \Xi\end{array}$ & 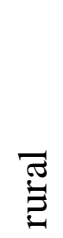 & 芑 & 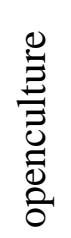 & raw & unique & & coverage & consistency \\
\hline 1 & $\bullet$ & & & O & O & 0 & O & & .17 & .00 & .86 & .51 & .83 \\
\hline 2 & $\bullet$ & & $\bullet$ & O & O & & & O & .26 & .02 & .90 & & \\
\hline 3 & $\bullet$ & O & $\bullet$ & & & O & & O & .17 & .03 & .88 & & \\
\hline 4 & ○ & 0 & & 0 & & 0 & 0 & & .17 & .01 & .87 & & \\
\hline 5 & • & $\bullet$ & & O & & $\bullet$ & & 0 & .12 & .00 & .87 & & \\
\hline 6 & & 0 & $\bullet$ & 0 & 0 & & 0 & 0 & .14 & .03 & .91 & & \\
\hline 7 & & - & 0 & O & 0 & $\bullet$ & 0 & & .09 & .01 & .87 & & \\
\hline 8 & & $\bullet$ & $\bullet$ & O & & O & O & O & .11 & .02 & .88 & & \\
\hline 9 & $\bullet$ & O & O & & O & • & & 0 & .10 & .00 & .88 & & \\
\hline 10 & - & - & & 0 & 0 & & 0 & 0 & .10 & .00 & .90 & & \\
\hline 11 & - & 0 & & & - & - & • & 0 & .10 & .01 & .90 & & \\
\hline 12 & ○ & • & & & 0 & ○ & ○ & 0 & .09 & .00 & .89 & & \\
\hline 13 & - & • & - & 0 & 0 & • & & & .11 & .01 & .90 & & \\
\hline 14 & 0 & $\bullet$ & 0 & $\bullet$ & & $\bullet$ & & 0 & .11 & .01 & .90 & & \\
\hline 15 & $\bullet$ & 0 & 0 & $\bullet$ & 0 & & $\bullet$ & 0 & .10 & .00 & .90 & & \\
\hline 16 & - & 0 & & - & 0 & 0 & - & 0 & .10 & .00 & .91 & & \\
\hline
\end{tabular}

Note: black circles "๑" indicate the presence of antecedent conditions. White circles " $\bigcirc$ " indicate the negation of antecedent conditions. The blank cells represent ambiguous conditions. Frequency threshold $=6$; consistency threshold $=.90$. 


\section{Table 7}

Truth table for CCPs - intermediate solution

\begin{tabular}{|c|c|c|c|c|c|c|c|c|c|c|c|c|c|}
\hline \multirow[t]{2}{*}{ Path no. } & \multicolumn{8}{|c|}{ Antecedent (symbol) } & \multicolumn{2}{|c|}{ Coverage } & \multirow[t]{2}{*}{ Consistency } & \multicolumn{2}{|c|}{ Solution } \\
\hline & $\frac{\mathscr{O}}{\frac{\mathscr{U}}{3}}$ & $\frac{\mathscr{o}}{\mathfrak{\Xi}}$ & $\frac{\pi}{0}$ & 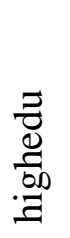 & 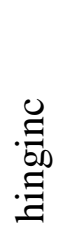 & $\underset{\Xi}{\overparen{T}}$ & 司 & 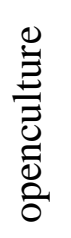 & raw & unique & & coverage & consistency \\
\hline 1 & O & O & O & & O & $\bullet$ & O & O & .05 & .00 & .89 & .12 & .83 \\
\hline 2 & O & O & $\bullet$ & & O & O & O & O & .06 & .00 & .91 & & \\
\hline 3 & O & O & $\bullet$ & O & & O & O & O & .06 & .00 & .89 & & \\
\hline 4 & O & O & $\bullet$ & $\bullet$ & & $\bullet$ & O & $\bullet$ & .06 & .00 & .89 & & \\
\hline 5 & O & O & & $\bullet$ & $\bullet$ & $\bullet$ & O & $\bullet$ & .06 & .00 & .89 & & \\
\hline 6 & $\mathrm{O}$ & O & O & $\bullet$ & - & O & - & O & .04 & .01 & .90 & & \\
\hline 7 & O & $\bullet$ & 0 & $\bullet$ & 0 & $\bullet$ & 0 & 0 & .05 & .02 & .91 & & \\
\hline
\end{tabular}

Note: black circles "๑" indicate the presence of antecedent conditions. White circles " $O$ " indicate the negation of antecedent conditions. The blank cells represent ambiguous conditions. Frequency threshold $=3$; consistency threshold $=.90$. 
Table 8

Truth table for GCPs - intermediate solution

\begin{tabular}{|c|c|c|c|c|c|c|c|c|c|c|c|c|c|}
\hline \multirow[t]{2}{*}{ Path no. } & \multicolumn{8}{|c|}{ Antecedent (symbol) } & \multicolumn{2}{|c|}{ Coverage } & \multirow[t]{2}{*}{ Consistency } & \multicolumn{2}{|c|}{ Solution } \\
\hline & $\frac{\stackrel{9}{3}}{3}$ & 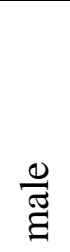 & $\frac{0}{0}$ & 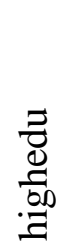 & 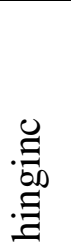 & $\underset{\Xi}{\overparen{Z}}$ & $\begin{array}{l}\stackrel{0}{0} \\
\text { D্ }\end{array}$ & 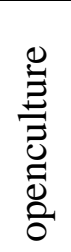 & raw & unique & & coverage & consistency \\
\hline 1 & 0 & 0 & 0 & 0 & 0 & $\mathrm{O}$ & 0 & 0 & .07 & .02 & .84 & .10 & .76 \\
\hline 2 & 0 & ○ & 0 & - & 0 & ○ & 0 & O & .08 & .03 & .81 & & \\
\hline
\end{tabular}

Note: black circles " $\bullet$ " indicate the presence of antecedent conditions. White circles " $\bigcirc$ " indicate the negation of antecedent conditions. The blank cells represent ambiguous conditions. Frequency threshold $=3$; consistency threshold $=.80$. 


\section{Table 9}

\section{Results of Multiple Regression Analysis for CCP•GCPs}

\begin{tabular}{|c|c|c|c|c|}
\hline & \multicolumn{2}{|c|}{ Regression Coefficient } & \multirow[b]{2}{*}{$t$-value } & \multirow[b]{2}{*}{$p$} \\
\hline & unstandardized & standardized & & \\
\hline Intercept & 4.240 & & 72.970 & .000 \\
\hline white & .129 & .044 & 2.755 & .006 \\
\hline male & -.094 & -.038 & -2.456 & .014 \\
\hline old & .282 & .116 & 7.303 & .000 \\
\hline highedu & -.435 & -.172 & -10.447 & .000 \\
\hline highinc & -.132 & -.054 & -3.308 & .001 \\
\hline rural & .154 & .060 & 3.768 & .000 \\
\hline repub & .018 & .007 & .440 & .660 \\
\hline openculture & -.256 & -.104 & -6.563 & .000 \\
\hline
\end{tabular}

Note: Dependent variable: CCP•GCP. Global F-test: F(8; 3820) $=42.685$ ( $\mathrm{p}<.001)$. Adjusted $\mathrm{R}^{2}=.080$. All antecedent variables dummy coded (on the basis of a median split where appropriate). 


\section{Table 10}

\section{Results of Multiple Regression Analysis for CCPs}

\begin{tabular}{|c|c|c|c|c|}
\hline & \multicolumn{2}{|c|}{ Regression Coefficient } & \multirow[b]{2}{*}{$t$-value } & \multirow[b]{2}{*}{$p$} \\
\hline & unstandardized & standardized & & \\
\hline Intercept & 4.016 & & 108.068 & .000 \\
\hline white & -.035 & -.020 & -1.168 & .243 \\
\hline male & -.052 & -.034 & -2.119 & .034 \\
\hline old & .015 & .010 & .593 & .553 \\
\hline highedu & -.011 & -.007 & -.426 & .670 \\
\hline highinc & -.033 & -.022 & -1.284 & .199 \\
\hline rural & .026 & .016 & .982 & .326 \\
\hline repub & .039 & .025 & 1.492 & .136 \\
\hline openculture & .037 & .024 & 1.469 & .142 \\
\hline
\end{tabular}

Note: Dependent variable: CCP (invert coefficients to receive the results for GCP). Global F-test: $\mathrm{F}(8 ; 3820)=1.687(\mathrm{p}<.1)$. Adjusted $\mathrm{R}^{2}=.001$. All antecedent variables dummy coded (on the basis of a median split where appropriate). 